\title{
Ciencia y fe, hacia un pensamiento integral: la propuesta de Raimon Panikkar
}

\author{
ZAIDA ESPINOSA ZÁRATE* \\ Universidad Loyola Andalucía (España) \\ zespinosa@uloyola.es
}

\begin{abstract}
Resumen
La cuestión de la relación entre ciencia y fe ha adquirido nuevo vigor en los comienzos del siglo, cuando, tras años de especialización y separación fragmentaria de los saberes, que conducían a la esquizofrenia cultural del cognoscente, se empieza a percibir de manera cada vez más nítida la necesidad de su integración para dar cuenta de la multidimensionalidad de lo real. Tras poner de manifiesto la aparente tensión entre cultura y trascendencia como realidades que conviven en el ser humano, se rastrea la posibilidad que $\mathrm{Pa}-$ nikkar propone de una ciencia que, sin eliminarse a si misma, sin cancelar la mediación que ella misma constituye ni despojarse de sus maneras y métodos propios, sin siquiera abandonar el plano de la pura inmanencia, reconoce en él lo divino: la infinita trascendencia del cuerpo -su carácter siempre abierto al misterio- y su infinita inmanencia -su profundidad insondable-. Esto tiene lugar en la forma concreta que el autor propone de una teofisica, de modo que con ella no ocurre algo semejante a lo que Wittgenstein indica respecto a la escalera de la que, una vez arriba -lograda la significación de lo Absoluto- puedo desprenderme, sino que, en ella, la escalera -la dimensión física- se conserva y se supera.
\end{abstract}

Palabras clave: ciencia, fe, Panikkar, conocimiento, cultura, trascendencia.

\section{Science and faith, towards a comprehensive thought: Raimon Panikkar's proposal}

\begin{abstract}
The issue of the relationship between science and faith has acquired greater relevance since the beginning of the century, time in which, after years of specialization and fragmentation of human knowledge, which have led to a cultural schizophrenia of the knower, there is a growing awareness of the need to integrate both to account for a multidimensional reality. After noticing the apparent tension between culture and the divine as realities that coexist in human beings, it is examined Panikekar's proposal of a science that, without eliminating itself, without cancelling the mediation that it constitutes, nor divesting itself from its own methods, not even without abandoning immanence, recognizes in itself the divine: the infinite transcendence of the body -its character always open to mystery-and its infinite immanence -its unfathomable depth-. This corresponds to the author's theophysics, so that, in it, it does not happen something similar to what Wittgenstein indicates about the ladder of which one can get rid once up -when the significance of the divine has been attained-, but in it the ladder-the physical dimension - is preserved and surpassed.
\end{abstract}

Key words: science, faith, Panikekar, knowledge, culture, transcendence.

* Doctora en Filosofía por la Universidad Complutense de Madrid. Es autora del libro Percepción, pensamiento y lenguaje. El realismo radical de Reinhardt Grossmann y el realismo moderado de Fernando Inciarte (2015).

Recibido: 15/Noviembre/2018 - Aceptado: 22/Noviembre/2019 


\section{1. ¿HOMO CULTURALIS Y HOMO RELIGIOSUS A LA VEZ?}

La cuestión de la relación entre fe y ciencia puede plantearse de manera más amplia al considerar la relación entre fe y cultura como actividad específicamente humana. Cultura es todo lo que el hombre hace. Como es bien sabido, el ser humano es un ser cultural, que vive en la cultura y no en la naturaleza bruta y originaria (Gehlen, 1980). Esto significa que es un ser creativo, eminentemente productor, que construye objetos, obras de arte, pero también teorías, modelos, hipótesis que configuran lo que actualmente consideramos como ciencia. Podemos construir teorías incluso para contextos inventados, sin relación a la realidad y, sobre la base de ellos, hacer enunciados demostrables dentro de tales contextos, pero falsos, sin correspondencia con la realidad. También el sujeto humano elabora lo que puede denominarse un 'pensamiento' cristiano, que es también construcción intelectual (Panikkar, 2009). Todo esto son mediaciones que sirven para dar cuenta de mundo, para manejarlo y hacerlo soportable: constituyen la manera humana de habitarlo.

La pregunta que se nos plantea es acerca del alcance - ¿inmanente?, ¿trascendente? - de esta acción cultural creativa bumana y de sus productos, entre ellos, los de la ciencia en específico y, por tanto, de sus límites expresivos. ¿Puede la ciencia, en concreto, acoger a Dios y entenderse como expresión y deseo de Él o, por el contrario, constituye una objetivación que prescinde de lo divino o pretende sustituirlo? ¿Puede la ciencia mostrar, sin necesidad de ir más allá de sí, algo absoluto, o consiste en un complejo sistema de signos que no remiten más que a sí mismos?

Esta cuestión supone una reedición del agitado debate escolástico respecto a las relaciones entre razón y fe, pero aquí nos proponemos examinar un tipo de racionalidad particular, la científica. La disputa medieval fraguó en posturas de ensalzamiento, e incluso exclusividad, de la una frente a la otra, o en la teoría de la doble verdad, que hoy en día perdura en "la esquizofrenia cultural de nuestro tiempo", es decir, en una "fragmentación del conocedor" a la que nos ha llevado "la fragmentación de los conocimientos" (Panikkar, 2009: 75), que son adjudicados a compartimentos estancos por la razón procedimental de nuestra época.

$\mathrm{El}$ dilema es agudo, pues afecta radicalmente a la propia identidad humana y, en tanto que tal, exige necesariamente una toma de postura. Fernando Inciarte (2016) lleva al límite esta tensión que se vive en el corazón humano: ¿tiene el cristiano que despreciar, en cierta medida al menos, el mundo y, en consecuencia, su propia razón creadora, para amar auténticamente a Dios? ¿Es el deseo de cultura, de ciencia para erigirse en señor de 
la realidad, síntoma -además, fácilmente contagioso- de enfermedad anticristiana, o puede contener la aspiración a la trascendencia la voluntad del poder que otorga el conocimiento científico?

Podemos hacer referencia al modo de vida de los cristianos primitivos, los arameos monofisitas. De ellos dice Inciarte que vivían de manera sumamente sobria, insultantemente simple en lo que se refiere a esa dimension cultural creadora característicamente humana: ellos tenían una pura religión sin cultura. Esto supone eliminar todo tipo de mediación, a saber, no sólo el arte, sino también la teología: "No es que sean ellos mismos iconoclastas. En sus iglesias tienen también imágenes, pero la calidad artística de esas imágenes es algo que les tiene literalmente sin cuidado" (Inciarte, 2016: 38). Consideraban el mundo de tal manera como meramente pasajero y transitorio y, en consecuencia, como tan radicalmente insignificante, que la situación del hombre en él y su cuidado era hasta cierto punto indiferente. No es desprecio del mundo necesariamente, sino completo desinterés. Ahí simplemente no está lo que importa. Este es el sentido de la consideración de la curiositas como pecado: "El deseo de indagar aquello que es irrelevante para la plenitud de la vida humana" (Panikkar, 2009: 41).

La pregunta que se nos plantea, entonces, es: ¿se puede ser cristiano de verdad y a la vez profundamente científico y, en definitiva, ser cultural, creador que se regocija en el mundo, que cultiva la cultura como expresión del deseo de vivir humanamente de manera plena para hacer habitable el entorno, pues, a pesar de todo lo efímero que este sea, constituye estación por la que necesariamente hay que pasar?

En base a esta ambivalencia que vive el que se recrea en el mundo y que, a la vez, lo percibe en esencial contraposición a lo Absoluto, se puede ver cómo adquiere sentido plantear la relación entre cultura en general dentro de la cual encontramos la actividad científica-, y trascendencia, para determinar si a través de aquella el ser humano puede no solo quedarse en síy en el mundo que le rodea, sino ir más allá de ello.

Para abordar esta cuestión es necesario que precisemos qué es la fe en la concepción de Panikkar, por un lado, y, por otro, qué es lo que actualmente entendemos por ciencia y en qué consiste la cultura científica contemporánea que hoy está envuelta de prestigio e invade todas las áreas, pues esta ha evolucionado mucho en el paso del tiempo respecto a la episteme griega. Merece la pena detenerse en la propuesta de este autor en el que ha sido declarado como el "año Panikkar", centenario de su nacimiento (Cirlot, Melloni, Tamayo \& Saranyana, 2018). 


\section{LA FE COMO DIMENSIÓN CONSTITUTIVA HUMANA}

Para Panikkar la fe constituye una dimensión fundamental del hombre por la que necesariamente aparece el cuestionaminento por lo Absoluto. Es fundamental u ontológica porque "no solamente es necesaria para comprender [crede ut intelligas], sino también para alcanzar la plena humanidad, para ser" (Panikkar, 2007: 200). Esto es así porque no consiste, frente a lo que podría pensarse, en una relación exclusiva con un Dios aislado, sino que pasa por reconocer la ligazón con toda la realidad, desde sus vículos ontológicos fundamentales de solidaridad. Panikkar distingue lo que denomina actitud religiosa de la religión como institución humana (Martínez Bejarano, 2016), y desde esta diferencia se comprende la historicidad de estas últimas y la llamada a su autoexamen, e incluso a su conversión a las verdades de otras religiones a través del diálogo interreligioso, frente a la universalidad de la primera como actitud connatural del ser humano. El acto de fe como acto antropológico primordial (Panikkar, 2016) le permite conquistar la libertad que le otorga la instalación en una relación personal, rompiendo con una existencia puramente cósmica, esto es, anclada al mundo de las meras cosas (Panikkar, 2007). Desde esta perspectiva, la actitud de conversión consiste en un ejercicio de recuperación de la relacionalidad originaria de lo real -religación-, sin que esto afecte a la ontonomía de cada ser (Fundación Vivarium Raimon Panikkar, s.f.). Convertirse al otro significa, entonces, descubrir que el "'caso' contiene en su interior una referencia constitutiva, una valencia abierta, una relación esencial con el todo" (2009: 146) y transforma el individuo en persona (2006b).

La fe se manifiesta en un conjunto de creencias más o menos integradas. Pero no consiste en mera obediencia acrítica a la autoridad, "una especie de simple aceptación de las 'verdades de fe' o de los 'datos revelados" (Panikkar, 2009: 104), sino "escucha inteligente al conjunto de las fuentes de verdad del hombre: la triple empireia de los sentidos, de la razón y de la fe, implicados los tres en la misma experiencia" (2009: 54-55), que "entreabre la posibilidad de la perfección, permitiéndonos llegar a ser lo que todavía no somos" (Panikkar. 2007: 199). A esta experiencia la denomina Panikkar "mística", como experiencia de integralidad en un doble sentido: en tanto que pone en juego todas las facultades de la persona, y en la medida en que su objeto no es exclusivamente lo divino, la experiencia de Dios - una sola dimensión de lo real-, sino que es también integral, a saber, la realidad completa, abordada de manera holística (Panikkar, 2005).

Por tanto, si no es obediencia ciega, "la fe es también conocimiento [gnôsis], aunque distinto del científico" (Panikkar, 2009: 15, 60). Es decir, es un conocimiento que no se basa en la evidencia racional, sino que sobrepasa nuestros propios límites para "entrar en la benevolencia creadora 
de Dios" (Vilanova, 1993: 20), pero que no la niega o elimina. Es decir, la supera, la completa y enriquece sin ir en contra de ella. En efecto, según Panikkar este enriquecimiento es de estricta necesidad para el hombre contemporáneo, que percibe de manera cada vez más patente las insuficiencias de la razón fragmentada a la que ha conducido el racionalismo (Sánchez Cañizares, 2008): "La razón debe ser ciertamente superada, pero no borrada" (Panikkar, 2009: 59). Esto significa introducir la mística en toda experiencia humana (científica, filosófica, ética, cotidiana, etc.), que es la única manera de, primero, volverla verdadera, comprometida y encarnada, esto es, integral o relacional y, segundo, recuperar la propia naturaleza de su sujeto (Panikkar, 2005). Podemos rastrear tres motivos a los que Panikkar alude para dar cuenta de esto:

(1) En primer lugar, "conocimiento no equivale a conocimiento racional, así como racionalidad no equivale a inteligibilidad. Hay muchas formas de racionalidad, pero también hay muchas formas de inteligibilidad" (Panikkar, 2009: 80). Que el conocimiento, la comprensión o la inteligibilidad no puedan identificarse con el conocimiento racional se debe, a su vez, a dos razones:

Por una parte, a que la realidad no es enteramente objetivable racionalmente. Esto ocurre porque, primero, el sujeto es parte de ella, y de él no se puede lograr una plena objetivación. Millán-Puelles se refiere a esto al hablar del carácter inadecuado de la conciencia de la subjetividad:

La efectiva adecuación de esta conciencia es por completo imposible porque es imposible la plena conversión de la subjetividad 'connotada' en subjetividad 'objetivada'. O lo que es igual: si un ser que no es conciencia no puede aparecerse por completo, es porque no le es viable una perfecta y absoluta reflexión, lo cual a su vez se debe a que la índole de sujeto o sustrato de conciencia, que corresponde a este ser, es meramente consectaria de los actos en que él se aparece. (1967: 130)

$\mathrm{Y}$, segundo, por el radical dinamismo de lo real, frente al carácter más o menos rígido o estático de los conceptos racionales, debido a que el conocimiento racional procede objetivando aquello con lo que se encuentra.

Por otra parte, la fe busca -y es en sí misma- una forma de inteligibilidad, de comprensión: es sentido en sí: "Así como la vida intelectual va más allá que la vida de los sentidos, la vida de la fe no puede limitarse a la vida racional. La simbiosis es imperativa" (Panikkar, 2009: 58).

Panikkar denuncia la preponderancia casi absoluta de la racionalidad en la modernidad occidental hegemónica. Advierte que existen distintas visiones del mundo o cosmologías, distintas experiencias de él, es decir, 
diversos mythos fundamentales que no cabe ignorar ni tampoco meramente abordar desde el propio logos, subordinándolos a la racionalidad de nuestra cultura occidental, como si ella constituyera el centro, criterio o marco de referencia legítimo de observación. De otro modo se perpetua el "monoculturalismo colonialista" de la actitud moderna, del que ha derivado el "fundamentalismo laicista" al que asistimos en nuestro tiempo (2005: 96). El pluralismo de estos modos de inteligibilidad delata la relatividad de la propia cosmovisión, que, sin embargo, no debe confundirse, como él mismo aclara en numerosas ocasiones (1993a: 328; 2009: 83), con relativismo, ni degenerar, por tanto, en escepticismo. Si bien el examen crítico del propio modo de acceso a lo real desde sus presupuestos es radicalmente necesario como momento transitorio o provisional de escepticismo para evitar los peligros del dogmatismo, este no se puede constituir en estación o parada definitiva del pensamiento, ya que no concuerda con su afán incansable de sentido. De hecho, reparar en la relatividad de la cosmovisión en la que vivimos constituye el medio para hacer lo mismo respecto a "la vulnerabilidad, los límites [de la persona], la condición humana" (Vilanova, 1993: 22-23), en definitiva.

Así pues, no es la constatación del pluralismo de los modos de inteligibilidad de lo real lo que aboca al relativismo. Según Sánchez Cañizares, ha sido precisamente la afirmación de la exclusividad de la razón lo que ha llevado paradójicamente a él, como se ha puesto de manifiesto en el devenir del movimiento racionalista. Más que hipertrofia de la razón, este consistió precisamente en "reducción, autolimitación de la misma" como propuesta metodológica que, al acabar "autoimponiendo límites de principio a la propia razón", condujo a la pérdida de su "capacidad integradora para difractarse en una pluralidad de razones procedimentales" (Sánchez Cañizares, 2008: 862) que acabó en una "progresiva pérdida [...] de todas las certezas" (Maritain, 1942, s. p.).

Para evitar el totalitarismo de la razón como epidemia heredada de la modernidad occidental, Panikkar propone en su hermenéutica diatópica un método de diálogo no dialéctico, sino dialógico o dialogal (Gómez, 2015; Panikkar, 1993a; 2009). Este tiene la virtualidad de que tiene lugar "entre sujetos", mientras que aquel es "sobre objetos" (Gómez, 2015: 35). Es decir, se trata de un "diálogo vital que compromete a toda la persona... donde cada uno busca comprender el corazón del otro" (Vilanova, 1993: 19), se da "el descubrimiento de una interioridad recíproca" (Vilanova, 1993: 23). Como se dijo más arriba, el conocimiento racional es siempre objetual, procede objetivando aquello con lo que se encuentra, y en este pensamiento objetivizador se aprecian las limitaciones ya señaladas.

En definitiva, "del mismo modo que el ser no puede identificarse con el logos [como más abajo veremos], el ser humano para Panikkar no se agota 
en la razón" (Gómez, 2015: 35). Aquello que puede abarcar lo real es solo el espiritu, que es libertad, y por ello puede este abarcar la libertad de lo real, libertad óntica. Para ello hay que trascender la actividad puramente mental, ya que el intelecto no puede admitir aquello que considera equivocado, mientras que el corazón sí es capaz de abrazar al que considera estar en el error: "El logos representa la gran dignidad del hombre, pero existe también el espíritu -que no está subordinado al anterior" (2006b: 14, 51).

(2) En segundo lugar, no sólo hemos de relativizar la razón y sus productos, superándolos sin negar su intrínseca validez, sino que conviene notar también la identificación prevalente de racionalidad con racionalidad científica. A esto replica Panikkar (2009: 82) que "no toda la realidad es científicamente pensable; existen otras formas de pensamiento que nos desvelan otros aspectos de la realidad", lo cual no debe llevar a una actitud de condena de la ciencia, sino a una emancipación de su dominio (Panikkar, 2006a).

La racionalidad admite muchos modos, y por ello hemos de ampliarla (Kasak, 2018) para dar cuenta de lo que no es puramente cuantitativo o reducible a ello y expresable en términos matemáticos. Lo verosímil, lo que no es objeto de una estricta demostración apodíctica, de pura certeza matemática ni procede more geometrico, también forma parte del campo de lo racional. Hay "un espacio libre entre la verdad absoluta y lo falso para que lo ocupen esas verdades generalmente aceptadas que son buenas razones pero que están y deben estar siempre sujetas a revisión" (López Eire, 1995: 888). Este espacio corresponde a la ética y, en general, a todas las ciencias humanas, que no "se prestan a la formalización basada en verdades necesarias y universalmente convincentes. Pero no por eso [...] había que dejar tales cuestiones fuera de los confines de la lógica y de la razón" (López Eire, 1995: 886), en línea con la distinción aristotélica entre un razonamiento estrictamente demostrativo y otro dialéctico, basado en la plausibilidad. También Benedicto XVI señala la necesidad de un ensanchamiento de los espacios de nuestra racionalidad para dar cuenta de la complejidad del ser humano y, en último término, de lo real (Sánchez Cañizares, 2008).

(3) En tercer lugar, la expansión del concepto de racionalidad, e incluso su superación y enriquecimiento mediante otras fuentes de inteligilidad, no aseguran la conmensurabilidad del pensamiento respecto de lo real: "No toda la realidad es pensable; y, aunque exista un pensamiento no científico que nos abra a la realidad, el pensamiento no agota ni el Ser ni la realidad" (Panikkar, 2009: 78-79, 82).

Esto es, en cualquier caso, el orden del ser no es paralelo al orden del pensar, "la realidad misma no es auto-inteligible" (Gómez, 2015: 28), sino que el on es más amplio que el logos, hay un "sustrato incomprensible de la 
comprensión” (Panikkar, 1993a: 332). Panikkar alude a este aspecto bajo la idea de la libertad óntica: "El ser no necesita tener o serguir leyes, por útil que esto pueda ser. El ser no se restringe exclusivamente a lo que el pensamiento postula" (1999: 33). Pero es precisamente esta resistencia de la cosa a ser conocida la que "nos está revelando que ella es real. Si fuese totalmente transparente, sería invisible (incognoscible)" (Panikkar, 2009: 78). Y más adelante: "Todo ser es un misterio. La mística es consciente de ello. La noche, la vacuidad, las tinieblas, hacen posible la luz, la gnôsis" (2009: 79). Precisamente en tanto que la cosa se retira, se nos da. Esta es la ambivalencia o dualidad que afecta a la realidad en su carácter intrínsecamente apariencial.

Por otra parte, si la fe es conocimiento, es también, como él, un acto de libertad. En efecto, es libertad conquistada, no meramente dada o libertad negativa, porque la verdad es fruto de una conquista que no es pacífica para el hombre, sino que implica lucha: una lucha contra algunas inclinaciones, de dominio y resistencia frente a ciertas tendencias para no ser esclavo de ellas (Gervilla Castillo, 2003). Desde esta perspectiva se entiende la bidireccionalidad entre libertad y verdad o, puesto de otra forma, el círculo que se genera entre ellas: por un lado, la verdad hace al hombre libre, de modo que "si el hombre no está en condiciones de conocer la verdad, entonces no puede ser libre" (Llano, 2013: 217). Es decir, el conocimiento (no sólo racional) es tal para la libertad, porque constituye una de las pocas realidades humanas que no es natural, al no estar sometido a la necesidad o causalidad natural del mundo físico. Todo lo demás, "lo que no es conocimiento, incluso el lenguaje, es influjo" (Llano, 2013: 217). Y, por otro lado, la libertad es la verdad del hombre, en tanto que este es un ser que está más allá del mundo estrictamente natural.

Por otro lado, si la fe no es conocimiento exclusivamente racional, ha de emplear un lenguaje distinto al de la razón: el simbolo, que no es reducible a conceptos. La diferencia entre ambos se examinará más abajo. Además, por no ser puramente racional, no se puede decir que se apoye primordialmente en la información de la objetividad racional, sino que está basada en una experiencia espiritual subjetiva, personal o existencial, y tiene por ello un potencial transformador de la vida. Esto significa, por un lado, que "no puede contentarse con ser 'fe' en la fe de los demás, confianza en el testimonio de algunos privilegiados" (Panikkar, 2009: 54) y, por otro, que no es puramente intelectual, concerniente sólo a esta dimensión humana, sino que trasciende el mundo mental: es vivencial, lo cual no significa, como se ha dicho arriba, que ignore o niegue la actividad de la razón. Otra forma de expresar esto consiste en decir que "la fe sin obras está muerta... Sin la contribución de la sensibilidad, de la inteligencia y del "tercer ojo"... es superstición y no es capaz de sostener una vida" (Panikkar, 2009: 55). 
Este carácter experiencial de la fe implica que no está desgajada de la realidad, sino que se refiere a la "visión de la realidad como un templo, símbolo de la morada humano-divina, como algo sagrado -la "sagrada secularidad" (Panikkar, 2009: 105), pues lo divino no es puramente trascendente y extraño a la realidad, sino que está en ella misma, es "inmanente a la realidad material". Esta es la "dimensión teológica de la creación material" (2009: 106) por la que puede reconocerse un fondo divino en todo lo real: en el cosmos y también en el hombre. "«Lo divino abraza la naturaleza entera»", recoge Panikkar (2009: 153) de Aristóteles. Esta constituye la aportación central de la propuesta de Panikkar en la forma de su visión o intuición cosmoteándrica (Panikkar, 2009: 63) hacia la que considera que actualmente se avanza, en la dirección de una superación de los dualismos que separan a Dios del mundo, al hombre del cosmos, y al hombre de Dios.

Signo manifestativo de que las cosas están cambiando es que cada vez se percibe con más nitidez el lado sagrado de la naturaleza, como se manifiesta en la nueva sensibilidad ecológica que está proliferando con paso firme en el mundo actual (Panikkar, 1993a). El reconocimiento del hombre contemporáneo de que "ya no es el dueño del universo" (1993a: 329) y, "en lugar de comportarse como saqueador..., empieza a actuar como un administrador más humano ante la "madre tierra" (Panikkar, 1993b, s. p.), como "colaborador o administrador responsable" (Panikkar, 1993a: 329), así como la creciente preocupación por la justicia, la alimentación, la salud y la paz en la tierra, manifiestan los inicios de un cambio más profundo: "una nueva sensibilidad respecto del cuerpo, la materia, sociedad y el mundo entero" (Panikkar, 1993b: s. p.), según la que se comienza a comprender la radical integración de lo cósmico, lo humano y lo divino que, como elementos distintos o realidades específicas pero entrelazadas, constituyen el ritmo del ser, dejando atrás los exclusivismos que los aíslan.

Panikkar repara en que la fe cristiana, cristalizada en pensamiento, constituye todo un mundo cultural, una forma mentis que ha configurado el modo de pensar de las sociedades modernas secularizadas: "El sentido de la historia, la convicción de una dualidad entre espíritu y materia, la noción de la temporalidad lineal y la consciencia de la individualidad" (Panikkar, 2009: 36-37), así como la noción de un Dios personal, de la realidad del pecado en su relación con el problema del mal, o la idea de dignidad humana son aportaciones cristianas a nuestra cultura (Orrego Sánchez, 2015), de modo que estas "actúan en el mismo marco del mythos cristiano, aunque a veces en oposición dialéctica" con su logos (Panikkar, 2009: 37). 


\section{EL PENSAMIENTO CIENTÍFICO}

El pensamiento científico, como cualquier otro tipo de pensamiento, constituye una cierta construcción: construcción intelectual, obra de la razón, actividad de la mente. Es decir, es abstracto, representa un acceso mental o lógico a lo real, y esto significa que opera de forma categorial: subsumiendo lo real en categorías más o menos estáticas o rígidas, lógicamente construidas. Es importante reparar en este caracter construído o abstracto de los productos racionales, ligados al lenguaje y la cultura a la que se pertenece, pero sin que se agoten en ello (Inciarte, 2016).

Además, los productos de la ciencia resultan de una razón entendida de una manera particular o restringida: de la razón matemática, la cual se refiere exclusivamente a un aspecto de la realidad: su dimensión medible o cuantificable (Panikkar, 2009: 13), de modo que abstrae de todo lo demás, se abstiene de pronunciarse sobre ello, aunque son frecuentes las injerencias del pensamiento científico en terreno metafísico por las que, al descubrir cierta conexión legal entre fenómenos de tipos distintos, se acaba reduciendo uno de ellos al otro (García Norro, 2014). "Sólo cuando el objeto del saber es cuantificable, y, por lo tanto, controlable, aunque solo sea estadísticamente, permite una interpretación científica" (Panikkar, 2009: 32). Desde esta demarcación o restricción de su objeto, se observa fácilmente cómo la ciencia moderna constituye "una forma particular y limitada no solo de aproximación a la realidad [una aproximación exclusivamente racional], sino también de pensamiento [de una racionalidad solamente matemática]" (Panikkar, 2009: 81).

Su carácter matemático implica que constituye un pensamiento calculador en tanto que se refiere al comportamiento de los fenómenos, a cómo estos tienen lugar (leyes y regularidades científicas), no al qué, a su esencia, frente a la ciencia o filosofía tradicional, que se autocomprendía como auténtico conocimiento, como asimilación comprehensiva de la realidad (Maritain, 1942; Panikkar, 2009). Es decir, aquella no pretende hacer ninguna afirmación metafísica, pronunciarse sobre "la naturaleza real de las cosas" (Panikkar, 2009: 103-104), y por ello se puede decir que, en último término, "ha abandonado la pretension de conocer" (Panikkar, 2009: 81) en sentido estricto. La primacía de este tipo de pensamiento en el mundo contemporáneo hace que creamos "que explicar la génesis de un fenómeno equivale a conocerlo" (Panikkar, 2009: 27), y así queda desarticulada del panorama epistemológico la necesidad de la pregunta específica por el

qué, que pierde su vigencia al haberse reducido a la cuestión del cómo. No cabe duda de que este enfoque en el comportamiento de los fenómenos 
permite predecirlos y controlarlos, lo cual constituye una forma de dominarlos que "es muy útil", pero sigue sin desvelar "el misterio de la cosa" (Panikkar, 2009: 53).

En concordancia con su modo de expresión matemática, la actividad científica emplea un lenguaje conceptual unívoco, que corresponde con la aspiración a las ideas claras y distintas de Descartes, pero esta vez referidas al mundo observable.

Por último, al igual que la fe cristiana cristaliza en un pensamiento que moldea la forma de comprender el mundo de aquellos influidos por él, también opera de forma semejante la construcción intelectual científica. En efecto, la ciencia "no es solo un conjunto de conocimientos, es una institución político-social; es también una forma mentis, un modo de ver la realidad y de interpretar los hechos y los sucesos que se presentan a la consciencia humana" (Panikkar, 2009: 27). Es decir, es una cosmovisión o mito como conjunto de certezas que compartimos que no cuestionamos y que tenemos arraigadas profundamente, que sirven de trasfondo sobre el que juzgamos la verdad o falsedad de todas las proposiciones: aquello que "creemos de tal manera [...] que no creemos ni siquiera que creemos en ello" (2005: 98). Corresponde a lo que Wittgenstein considera la imagen del mundo (world-picture), frente al conocimiento, para el que sí cabe la duda (Ariso, 2019), o a lo que Ortega denomina "creencia", frente a las "ideas" (Ariso, 2015). Panikkar nota cómo la ciencia moderna, a pesar de tener unos orígenes culturales concretos - de hecho, pone de relieve su carácter marcadamente "mono-cultural" (2009: 30)-, se ha convertido en paradigma de todo pensamiento, incluso convirtiéndose en la única forma de conocimiento y en el único modo de entender lo real. Se encuadra dentro del mythos de la modernidad que es el "mito supremo de la razón, la filosofía como opus rationis, la universalidad de la ciencia y la linealidad del tiempo" (Panikkar, 2009: 18). Por ello, aunque "la ciencia y las tecnologías que se desprenden de su campo no constituyan una tradición de espiritualidad o religiosa, [esto] no significa que de hecho no supongan una modulación concreta de la dimension espiritual" de la persona (Senent de Frutos, 2019: 90), pues se da una relación precisa entre tecnociencia e interioridad.

La potencia o el atractivo de la ciencia moderna como trasfondo de certeza compartida desde el que operan todos nuestros conocimientos radica en su carácter flexible. Es decir, en que no fija ni se apega a ningún contenido concreto, sino que "puede vivir en la provisionalidad", pues "se sabe limitada, falible y provisional". Lo único absoluto en ella es su método. Es decir, "no fija sus propios contenidos; está dispuesta incluso a 
cambiar de paradigma, pero exige que se lo demuestren -dentro de los parámetros que ella misma reconoce". Es decir, "es suficientemente abierta y tolerante, pero dentro de sus propios límites" (Panikkar, 2009: 33).

En la medida en que constituye un pensamiento calculador dirigido fundamentalmente a establecer las regularidades de los fenómenos para predecirlos y controlarlos, está asociada con el producir, y se autocomprende cada vez más desde una razón instrumental que ha invadido todas las áreas (Heidegger, 1994; Taylor, 2016). Es decir, asume como criterio de verdad uno pragmático, a saber, la efectividad práctica de los productos que se logran a partir de ella.

\section{EL PRINCIPIO DE LA CIENCIA: LA PRESENCIA DE LO REAL COMO MO-} MENTO CONTEMPLATIVO

A pesar de la deriva instrumental de la ciencia, que ha llevado a que pongamos a la racionalidad científica el segundo apellido de 'técnica', ha de notarse que la actitud científica parte necesariamente de una captación o comprensión fundamental de la realidad de las cosas. Es decir, incluso a pesar de que "el pensamiento científico no se plantea la cuestión metafísica, el problema del ser, sino de manera indirecta..., no puede dejarlo de lado" (Panikkar, 2009: 53). Hay necesariamente en él, como elemento constitutivo de su estructura de sentido, un momento contemplativo que sirve de raíz para que la racionalidad productiva a la que da lugar se ponga en marcha. Es decir, la actitud científica que enfatiza y pone valor exclusivamente en lo expositivo, lo objetivo, impersonal y susceptible de evaluación, prescindiendo del aspecto experiencial y de la vivencia subjetiva, arranca y presupone inevitablemente un momento contemplativo como experiencia existencial que se refiere a la presencia de la realidad elemental, bruta y originaria como algo independiente de la conciencia que nos afecta de manera irremediable, incluso al margen de la propia voluntad. De este modo reparamos en la dimensión de fatalidad de la vida humana (Ortega y Gasset, 1983), en el hecho de que nos vivimos de manera pasiva respecto a algo que nos afecta, es decir, recibimos determinaciones naturales de lo externo, nos vivimos instados por ello, percibimos la causalidad en acto de los seres corpóreos en el yo (Millán-Puelles, 1967), de modo que no todos los significados son humanamente construidos.

Así se pone de manifiesto el carácter reiforme del sujeto, su radical facticidad y finitud, el hecho de que somos determinables físicamente. En definitiva, la condición trágica bumana: el dolor físico, la necesidad biológica (Millán-Puelles, 1967: 385), pero no solo esto, sino también el trabajo esforzado de su actividad, la constatación de que el deseo de cultura es lastimoso y laborioso, mientras que los dioses asisten a banquetes y celebran 
fiestas, como dice Platón (1871) en el Fedro, 246. Piirto, estudiosa estadounidense de la creatividad, se refiere a lo que denomina la "Regla de los diez años", según la que "uno ha debido estudiar un ámbito durante aproximadamente diez años antes de que pueda hacer una contribución original" (2011: 10), y también afirma que son necesarias 10.000 repeticiones antes de que se pueda llegar a un trabajo creativamente logrado, pues este requiere de una cierta automatización y del estudio formal del campo en el que se inscribe la acción creativa. No cabe duda, entonces, del carácter trabajoso y en algún momento penoso de la acción cultural.

Esta condición trágica se manifiesta de la forma más palmaria, como compartida, pero vivida en primera persona, en la realidad de la muerte, en el hecho de que todos nos vamos a morir. La originalidad humana radica precisamente, como afirma Karen Armstrong, en que, "a diferencia de otros animales, tenemos que vivir siendo conscientes de nuestra mortalidad, de nuestra muerte ineludible" (Nieto, 2 de noviembre de 2018), y en la propia pregunta por la identidad humana desde este hecho se manifiesta su dignidad. "Somos seres que nos hacemos preguntas", mientras que "los perros, por ejemplo, no se preocupan por los sufrimientos de los otros perros en otras partes del mundo, ni tampoco piensan si deberían ser amigos de los gatos". Y "nos olvidamos con frecuencia de que la misma pregunta [¿Qué es el hombre?] es la respuesta. El hombre es ese ser que se pregunta ¿Quién soy?” (Nieto, 2 de noviembre de 2018); es decir, la propia "pregunta constituye su dignidad" (Panikkar, 2009: 50).

La conciencia de la propia mortalidad constituye el acicate o el impulso que agita la normalidad de la vida ordinaria, que afecta de manera radical, experiencial y no meramente teórica a la voluntad individual. Desde ella arranca la posibilidad de un intento de comprensión científica del mundo que no absolutice el horizonte humano, al que se percibe ahora, desde esta perspectiva parcial, como esencialmente finito. Es decir, la conciencia de la posibilidad de la muerte a lo largo de la vida -por la que esta nunca es del todo ajena a aquella- constituye el aguijón que puede servir como catalizador o principio de una aproximación al mundo abierta a la trascendencia.

En efecto, la ciencia trae la muerte a la presencia en diversas manifestaciones, la hace presente como la nada del yo en su máxima individualidad, o al contemplar lo meramente posible precisamente en tanto que tal, ya sea de manera aislada, ya sea tomando en cuenta el conjunto de todas las posibilidades puras. La experiencia de ser mera posibilidad, de la pura contingencia en primera persona, de la no necesidad del yo, deja ver la oposición metafísica fundamental entre ser y nada, de la que ha de partir el científico al ocuparse precisamente de lo que es. Así deja atisbar lo radicalmente otro a todo aquello, a lo contingente, que no sólo o no necesariamente está fuera de ello, 
según Panikkar, y por ello puede impulsar, desde su modo de abordar lo real, al natural preguntarse por lo absolutamente necesario. Desde sus propios parámetros se puede abrir la pregunta, que ella misma no acaba de responder, pero sí abrazar, por la trascendencia.

\section{UNA CONDICIÓN TRÁGICA ELEVADORA}

$\mathrm{El}$ individuo que se encuentra en la tesitura de esta conciencia descubre la tensión más característica que hay en él que le saca de la cotidianeidad. Modificando la metáfora que Unamuno emplea en En torno al casticismo, podríamos decir que, si la vida humana es el mar, habitualmente el sujeto vive en la superficie como actualidad curiosa, volcado a lo otro que se aparece (Quevedo, 2013), pero debajo de ella se encuentra todo lo que la soporta: no sólo la historia, sino los acontecimientos significativamente humanos que descubren la gravedad de la existencia. La falsedad brota del esfuerzo de intentar quedarse sólo en la superficie como vida inauténtica o no examinada.

En el acceso a esa gravedad se vive la ambivalencia en las inclinaciones que afectan al sujeto, que es una expresión de la paradoja fundamental humana. Esta radica en que, en el reconocimiento de su facticidad y contingencia, en la vivencia del límite con el que se topa ante el dolor, el sufrimiento, la limitación y los fracasos frecuentes, que se constatan en el mismo hecho del cansancio físico, en definitiva, en la experiencia de la finitud bumana, se descubre lo más profundo del yo, que consiste en su afán de absoluto, su deseo de lo infinito o aspiración de trascendencia. Esta inclinación le lleva a un movimiento incansable del querer que no se posa, que no se colma ni conforma con relatividades pasajeras. Es la experiencia de vivir en una trinchera: su sensibilidad está herida por el fuego cruzado de una racionalidad opaca, que absolutiza el horizonte humano, que seduce con promesas de dominio de la naturaleza, de felicidad inmanente, en la tierra, y de una racionalidad abierta a lo Absoluto, que lo acoge como explicación última de lo real y "parte" de ello mismo.

Entonces puede ocurrir lo que Jane Piirto explica respecto al proceso de crear, que ahora podemos aplicar también al proceso de creer: "Lasitud, pereza, inercia -todas operan frenándonos a crear [creer]. El rechazo, la indiferencia y la crítica de otros también frustran la creatividad [fe]. El miedo a crear [creer] también juega un papel en la obstrucción del proceso creativo [de fe]" (2011: 8-9).

Es decir, en la experiencia vivida a menudo se da el deseo de una vida más cómoda y simple, lo cual significa una vida alejada del reto y del riesgo y el fracaso de la incomprensión. Pero, por otra parte, la tendencia a buscar respuestas absolutas resulta imperiosa (Piirto, 2011). Como ocurre con el 
poeta, tal y como Platón lo presenta en la Apología de Sócrates, en el Ion o en el Fedro, este tiene que crear como si de una necesidad o de una obsesión se tratase, de modo que pareciera que no es dueño de su libre voluntad y de la decisión creadora, sino que es la Musa la que se apodera de él y lo emplea para expresar el arte a su través. Algo semejante ocurre cuando el sujeto humano descubre en lo real su carácter divino: del propio cosmos y de sí mismo.

Ciertamente, la actitud radical ante este reconocimiento exige tomar riesgos: emprender el camino del pensamiento divergente y revisar de manera novedosa lo que ya es sabido para ir más allá de ello, frente a la asimilación acrítica o la conformación a las respuestas disponibles. Los peligros de este camino en el que se embarca el creador-creyente son evidentes, pero reconoce que esta constituye la única senda auténtica. Igual que ocurre con el proceso de crear, esperar que el proceso de creer esté exento de dificultades es tan falso como pensar que cualquier camino de aprendizaje es un camino de rosas, en el que el maestro entretiene, de una manera idílica, y hace felices a los que de aquellas enseñanzas participan, eliminando cualquier obstáculo y sin perturbar la calma. El esfuerzo y un cierto desasosiego son inevitables, pues siempre es más fácil quedarse donde uno ya estaba. La incertidumbre acerca de dónde llevará ese proceso supone dar un salto, pero la carga se vuelve más soportable si uno se sabe acompañado por algún Maestro. Y, como indica Piirto, "a menudo, la espina, la pasión que hiere o daña, también salva" (2011: 8).

Frente a una elaboración puramente intelectual de lo divino que pueda haber aportado cierta filosofía académica o profesionalizante y, desde luego, poco socrática, la aproximación humana más radical a la trascendencia tiene lugar desde un acceso netamente individual y experiencial. Sólo esta manera de aparecerse lo divino tiene una virtualidad transformadora de la vida. Pero este punto de partida subjetivo no marca su destino o su campo de actuación definitivo: como ocurre con el científico, que no puede quedarse recluido en el laboratorio, sino que debe comunicar sus resultados, el creyente tampoco puede quedarse en el templo, es decir, en la sola vida privada, sino que la actitud religiosa consiste esencialmente en salir al mundo, como reacción ante las injusticias del Estado, para ayudar al otro. Así nacen todas las religiones, como sostiene Armstrong: "Como un intento para mejorar las cosas y decirle al Estado que hay que ayudar a los pobres y preocuparse por ellos". Si se queda en la esfuera privada, "se convierte en una forma de egocentrismo, de egoísmo e indiferencia" (Nieto, 2 de noviembre de 2018).

Al descender desde la superficie del ser hasta sus honduras se abre al sujeto humano otro horizonte como posibilidad para recorrer: la posibilidad de lo absoluto, de lo divino desde la propia ciencia, y el camino de la fe 
como otro tipo de conocimiento. Como Platón ya había dicho al hablar de la episteme, aunque también de la inspiración poética, estas tienen una función elevadora que nos saca del mundo meramente sensible. Es decir, a partir de sus comprensiones del mundo y del yo -que se retroalimentan y asisten mutuamente en su relativa parcialidad-, pueden alcanzar la posibilidad de una trascendencia.

Esta apertura de la ciencia a la trascendencia consiste, más que en un cambio en el contenido, en los qués de su aproximación a lo real, en un nuevo modo de vivirlos, en la adquisición de un cómo novedoso de la propia existencia, por lo que implica una cierta transformación personal que afecta al científico qua científico.

\section{LA CIENCIA OPACA}

Ciertamente, la experiencia de la condición trágica humana puede servir también de arranque a una concepción de la ciencia que cierra al hombre sobre sí en una actitud de control o dominio puramente humano del mundo, desde una voluntad despótica dirigida por el puro amor de sí, que pretende controlar y, en último término, eliminar la tragicidad de la vida, liberarla de sus penosos esfuerzos con la ilusión de un progreso ilimitado. Así se entiende el mundo como "dato a comprender y utilizar", como recurso, y no tanto como "don del que disfrutar y estar agradecidos" (Panikkar, 2009: 76), se desvela su misterio por su neta eliminación. Entonces la ciencia pretende volverse omnímoda, quiere abarcarlo y cubrirlo todo, y se vuelve, además, opaca: no deja ver más allá de sí, se vuelve espejo de sí, no trasciende, constituyéndose en el único absoluto. Sólo se quiere a sí misma. Esto es lo que puede reconocerse en movimientos como el transhumanista o poshumanista, que estiman que la evolución de las ciencias y las técnicas NBIC (nanotecnología, biotecnología, tecnologías de la comunicación y la información y ciencias cognitivas) ha permitido que el ser humano se trascienda o supere a sí mismo, al estar ahora en su mano su propio proceso evolutivo gracias a esas tecnologías materiales.

Resulta curioso leer estudios referidos a la certeza que tenemos todos en nuestra propia muerte: a primera vista podría parecer que esta constituye una convicción básica, compartida por todos los individuos mentalmente sanos; pero, si realmente fuera así, "si la gente estuviera realmente cierta de que morirán y de que pueden morir en cualquier instante, no debería aparecer como tan inesperado el ser diagnosticado con una muerte inminente, pues tal posibilidad estaría ya implícita y dada por descontado en la asunción de que uno puede morir en cualquier momento" (Ariso, 2015: 83). Por esto, parece que no estamos tan ciertos de ella. Más bien, la percibimos como algo que "puede ocurrir sólo de forma accidental" (Ariso, 
2015: 85), de modo que la consideramos como evitable y como algo que va a ocurrir a medio o muy largo plazo, por lo que su posibilidad se disipa en el horizonte y cancela así su operatividad. En palabras de Ortega, se cree en ella con fe muerta, es decir, de modo que estamos en esa creencia, pero sin que influya nuestra vida (Ariso, 2015).

Este modo de pensar, propio de una cultura que deja de lado la muerte, es responsabilidad de una autocomprensión de la ciencia moderna como dominio respecto a todo lo que nos afecta. Para constituirse en absoluto, la ciencia necesita negar la condición trágica del hombre asegurando que, con su avance técnico ad infinitum, logrará la superación por eliminación de todo problema humano. La vivencia de la limitación, de la insuficiencia o pobreza esencial le resulta, en efecto, intolerable e insoportable, y confía en que podremos combatir nuestra finitud entitativa; en que todo esfuerzo es, o será, técnicamente eliminable desde las posibilidades técnicas del presente y del futuro.

El error que comete el que exclusiviza la ciencia como modo de conocimiento es un error de soberbia, que viene por "un desconocimiento de la verdad de la insuficiencia humana" (Millán-Puelles, 2009: 535), frente a la actitud de admiración ante el acontecimiento del mundo, en el que se revela la verdad ontológica, la verdad del ser insondable. También Panikkar afirma que un conocimiento de este tipo, "un conocimiento sin amor 'infla', vuelve arrogantes" (2009: 12), cuando lo más propio de la realidad humana es su característico tener límites, que no pueden ser salvados o superados por eliminación a través de puentes tecnológicos, sino que son connaturales a ella de manera no sólo operativa, sino también entitativa. "No poner límites al conocimiento significa querer ignorar la condición "limitada' del hombre" (Panikkar, 2009, 159).

$Y$ hay que notar que la constatación de la finitud humana no nace realmente de una actitud de resignación, incapacidad o debilidad de espíritu, como a veces se ha dicho: "[En la filosofía humanista] la finitud es celebrada -desde el nacimiento, respetuoso del azar genético, al envejecimiento y a la muerte, pasando por los sufrimientos y los esfuerzos físicos y psicológicos que el individuo debe soportar gracias a la fuerza moral de su alma y a su capacidad de resignación y aceptación" (Hottois, 2013: 168). Más bien, aquella nace del reconocimiento de que la limitación es estructural a la conciencia inadecuada de la subjetividad. Por una parte, lo es a su conocimiento, en tanto que la verdad que le es alcanzable es siempre parcial, perspectiva y determinada por su condición material e histórica. Y, por otra, afecta también a su voluntad, en la medida en que muchas veces no hacemos el bien que reconocemos como tal y deseamos. Por ello, la idea de una mejora radical ilimitada de todas las capacidades humanas en base al progreso técnico-material es falsa, incluso aunque este crezca de forma 
exponencial, puesto que para acabar con los males morales del ser humano no sólo basta con un mayor grado de conocimiento $-\mathrm{y}$, menos aún, sólo técnico-, sino que también hay que educar la voluntad.

Por todo esto se observa la necesidad de recuperar la templanza, la prudencia y la justicia como virtudes regulativas del interés por conocer la verdad, como dice Millán-Puelles. En concreto, la primera frena la curiosidad impertinente que lleva a "experimentarlo o probarlo todo" (Millán-Puelles, 2009: 551). La segunda, la prudencia, permite que no solo se atienda a la sustancia del acto, sino también a sus circunstancias; y la justicia regula nuestro afán por el conocimiento posibilitando que este no se busque a toda costa, por ejemplo, a costa de tratar a la persona puramente como un medio. Desde esta perspectiva se entiende lo que Hans Jonas dice: que "tener poder para hacer algo no implica que haya que hacerlo" (Chavarría Alfaro, 2015: 105).

\section{UNA DIVERSIDAD DE LENGUAJES}

Es cierto que el lenguaje unívoco de la ciencia, representativo de qués, de cosas materiales o de la dimensión cuantificable de lo real (y, en consecuencia, no de aquello que de ningún modo es 'cosa') no es el más adecuado para expresar y, por ende, para conocer la dimensión trascendente que escapa al determinismo de la naturaleza física y supera los límites de la comprensión racional-demostrativa. Para ello, la imagen simbólica del arte, el lenguaje análogo de la metafísica y los símbolos de la fe son más apropiados. La analogía tiene la virtud, frente a aquel, de permitir un mejor acceso al Ser divino, en tanto que prescinde totalmente de los contenidos -que no coinciden en los analogados-para fijarse en la modalidad-que sí puede ser compartida-. Panikkar apuesta por una analogía de tercer grado, la equivalencia homeomórfica, que permite establecer relaciones entre elementos procedentes de contextos o mythos totalmente diversos y que, por tanto, no tienen funciones equiparables ni son traducibles de forma directa (Gómez, 2015). En la misma línea, la virtualidad del símbolo frente al concepto consiste en que, mientras que este último "individualiza, el símbolo conecta" (Panikkar, 2009: 99), de modo que su incorporación genera nuevas maneras de pensar necesarias "para salir de los callejones sin salida de nuestra situación cultural" (Panikkar, 2006a: 70).

Por tanto, no se puede decir en sentido estricto que el pensamiento científico en nuestra forma cultural represente directamente a lo Absoluto,

pero sí puede hacer aparecer la idea que apunta intencionalmente a ello, puede tener también lo divino en el horizonte de su sentido en tanto que no se comprende sólo a sí mismo como construcción meramente evasiva de la condición finita de su sujeto, como búsqueda exclusiva de la vida 
cómoda o del producto técnico placentero, sino que aspira también a reconocer el fondo sagrado de lo real como es en sí mismo. Sólo así "posee una ligazón con la divinidad" (Panikkar, 2009: 104), y se puede decir, por tanto, que esta "surge muchas veces en el interior mismo de la ciencia sin necesidad de ser importada desde el exterior" (2009: 93). Como señala Panikkar, "la visión científico-matemática de la realidad nos revela un aspecto de esta realidad y de la realidad última, no ciertamente en cuanto trascendente, sino en cuanto inmanente" (Panikkar, 2009: 104).

Esto ocurre cuando la ciencia pone en contacto con la realidad última de las cosas, pues en este momento, sin eliminarse a sí misma, sin cancelar la mediación que ella misma constituye ni despojarse de sus maneras y métodos propios, sin siquiera abandonar el plano de la pura inmanencia, reconoce en él lo divino. No ocurre entonces algo semejante a lo que Wittgenstein propone respecto a la escalera de la que, una vez arriba -lograda la significación de lo Absoluto- puedo desprenderme, sino que la escalera se conserva y se supera en la forma concreta que Panikkar propone de una teofísica. En esta se pretende reconocer a Dios en la propia experiencia científica. Sólo desde esta visión del mundo se puede comprender que:

Las cosas no son Dios, pero no son sin Dios. Dios no es parte de las cosas, ante todo porque Dios no tiene partes. El Creador (si queremos utilizar este lenguaje) no se retira tras el acto creativo. Creación y conservación son un mismo acto. La creación es un acto continuo -O, dicho de manera más tradicional, un acto eterno, tempiterno prefiero decir. Como ya hemos apuntado, la teofísica no sólo nos da una nueva visión de la física, sino también una nueva visión de Dios. (Panikkar, 2009: 103)

Ciertamente la percepción de la sagrada secularidad no es fácil o directamente accessible y requiere de una nueva conciencia (Panikkar, 1993b). Rebasar el campo de la pura mediación -mediación sin resto de inmediación, sin dejar atisbar en ella la inmediatez- es aquello que más cuesta cuando estamos viviendo de forma sola o meramente humana en el mundo. La pura mediación es, en efecto, el medio -el hábitat- más frecuente de la vida cotidiana, si bien no el único posible, como vemos. Es su cómo más frecuente, un cómo que consiste básicamente en qués puramente finitos, en la ocupación con los qués propios de una existencia rodeada de cosas solamente físicas y nada más. Pero en las posibilidades de la misma ciencia como teofísica está la de acercar la inmediatez, sin necesidad de prescindir en absoluto de sus contenidos específicos.

Para este fin, además de reparar en la dimensión o aspecto divino del cosmos como objeto de la ciencia, es necesaria también la comprensión de que su sujeto, el hombre -que no es ajeno al objeto de la ciencia-, a 
pesar de su condición finita y determinable, no es tampoco una pura cosa más entre las cosas meramente finitas, y sus actos no se agotan o disuelven en puros procesos caracterizados por la obtención de unos resultados a partir de ciertos estímulos -como ocurre en los procedimientos deterministas o en las transformaciones puramente materiales-, sino que es espiritu y, en consecuencia, libertad. Por ello se reconoce también en él "un fondo abismal, inasible e incomensurable" desde la consideración de su "infinita trascendencia -su carácter siempre abierto al misterio-", y "su infinita inmanencia -su profundidad insondable-" (Panikkar, 1993b, s. p.). Actos como el perdón, el amor o el conocimiento, que no tienen estrictamente hablando causas, esto es, no son respuesta a ningún estímulo, en tanto que ninguna condición es suficiente para ellos, son ejemplos de la libertad que el hombre es. Son pura novedad: no se dan dentro de una lógica del mercado, del intercambio, que es de tipo determinista o causal: el perdón se puede dar sin arrepentimiento (Papastephanou, 2003) y, por muy agradable que alguien sea, esto no provoca al sujeto que lo tenga que amar, ni el que sea desagradable empuja necesariamente a lo contrario, en lo cual se observa cómo el ser humano rebasa el mundo puramente natural.

Ciertamente esta comprensión resulta también costosa, en la medida en que la vida está tan llena o atiborrada de cosas, y de cosas tan complejas, que puede resultar difícil reparar en nuestra distinción de ellas (el mismo planteamiento de la pregunta de si las máquinas pueden pensar es signo de ello). Si el ser humano se comprende como pura cosa, ha de entender, en consonancia, que aquello que basta para satisfacerle son también cosas, quizá un número mayor de ellas o de mejor calidad, cosas incluso más sutiles como las que pretenden ser algunos productos culturales en sentido opaco o puramente inmanente, que se consumen en nuevos templos puramente humanos sin trascendencia. Pero es desconocer al hombre darle cosas sólo humanas.

En la comprensión de este modo peculiar de ser-divino- del hombre hacía radicar Platón la misión de la vida humana, la cual, en tanto que remite necesariamente a lo Absoluto, sólo adquiere pleno sentido en contacto con ello. Por ello reclama para aprehenderlo la necesidad del conocimiento (gnôsis), que va unido al amor, que no cancela, pero que supera el solo método científico (episteme) y constituye la base para la sabiduría ( $\mathrm{Pa}-$ nikkar, 2006a).

\section{DOS POSIBLES COMPRENSIONES DEL MUNDO}

Por tanto, frente a Nietzsche, para el que el mundo sólo habla de sí, de modo que lo eterno es el retorno de lo puramente finito, Inciarte (2004) 
distingue y compara dos concepciones que pueden tenerse de él y que $\mathrm{Pa}$ nikkar también aceptaría con ciertos matices.

En primer lugar, este puede presentarse meramente como mundo, como puro mundo, esto es, como esfera de la afirmación de lo solamente humano, que puede estar en contra de Dios o simplemente al margen de Él, como si aparentemente fuera algo además de Él. Desde esta perspectiva -y en el mejor de los casos en el que este mundo no fuera negador de lo divinoeste sólo podría ser una imagen representativa de lo Absoluto. Y, dado que las representaciones (frente a los conceptos, según Inciarte) son por definición imperfectas en su capacidad de remitir a aquello que representan, el mundo desde esta perspectiva no deja ver bien a lo divino. En efecto, "la imagen representativa se parece a su original sin llegar a serlo" (Inciarte, 2004: 187), puesto que a Dios en sentido estricto no se le puede representar, ya que no es 'cosa' en absoluto.

En segundo lugar, según Inciarte el mundo puede hacerse presente como creación en sentido metafísico, es decir, "prescindiendo de la ilusión de una realidad que sea algo de por sî" (2004: 187), esto es, mostrando su propia nada, su ser "nada de suyo" (2004: 186). Panikkar utilizaría otros términos y, en lugar de destacar la nada del mundo al lado de Dios, lo elevaría a Él al reconocer su aspecto también divino. Desde esta perspectiva se entiende el mundo no como representación de lo divino -en consecuencia, imperfecta o defectuosa-, sino como icono, el cual sí puede constituir una auténtica presencia de Dios, verdadera semejanza (similitudine) de Él, que no se asemeja meramente (frente a la representación sensible), por tanto, a aquello.

Inciarte hace corresponder estas dos concepciones a una "visión puramente científica o mundana de la creación, del mundo" y a una "visión metafísica o como creación" (2004: 186), respectivamente, que representa a su vez de manera gráfica con las imágenes del calor y de la luz: mientras que "el calor puede subsistir en el aire aunque la fuente del calor desaparezca" (2004: 186), no ocurre así con la luz. Esto último es lo que sucede respecto al mundo: "No se puede independizar, a diferencia del calor, de su fuente o principio" (2004: 186). Sin embargo, para Panikkar este hecho no habla a favor de la poca consistencia del mundo en sí y, en consecuencia, a favor de la ceguera estructural de la visión científica, frente a lo que Inciarte parece sugerir, sino precisamente de la radical interdependencia del cosmos y lo divino, por la que ambos no pueden quedar desligados. Inciarte también está de acuerdo en esta conclusión, pero a costa de haberlos primero separado hasta el punto de reducir el mundo, considerado por sí mismo, a una pura nada: de volverlo lo completamente otro a lo Absoluto.

En cualquier caso, desde la segunda perspectiva se alcanza la comprensión más elevada por la que se observa que "el mundo nos viene dado 
no como un objeto a indagar o como objeto de pensamiento [solamente], sino como don, como algo que nos abraza, en el cual podemos vivir y descubrir nuestros objetos" (Panikkar, 2009: 74).

Esta diferencia ontológica corresponde, en el plano cognoscitivo, con la que Panikkar señala entre com-prender y en-tender: "El comprender es racional y require la 'reducción' a una unidad inteligible. La razón fija y aprisiona su propio 'objeto'. Entender implica un entendimiento que supera la comprensión. En este caso el intelecto no aprisiona, sino que se aproxima a la cosa" (Panikkar, 2009: 72).

\section{CONCLUSIÓN}

En definitiva, el problema en el que nos encontramos inmersos probablemente viene de intentar someter la fe a la ciencia o viceversa (heteronomía), o de declarar la total independencia de ambas en una mera paz política o tolerancia en sentido negativo (pura autonomía), cuando ambas se refieren a órdenes distintos del ser, el cual "es polivalente y multiforme" (Panikkar, 2009: 16): "No se trata de subordinar ni la experiencia a la razón ni la razón a la experiencia (espiritual en este caso). La primera actitud es racionalista; la segunda, fideísta" (Panikkar, 2009: 55). A la necesidad de trascender ambas posturas se refiere Panikkar (1961) con el término de ontonomía, que alude a la superación de los dualismos y exclusivismos que han reinado en la historia del pensamiento (cosmocentrismo, teocentrismo y antropocentrismo) para captar el sentido holístico del cosmos, la interdependencia o relatividad radical de mundo, hombre y Dios en un pensamiento integral, no sectario, que no elimine la auténtica diversidad entre ellos y el respeto a sus leyes propias. Desde esta perspectiva no tiene sentido enfrentar ni filosofía y teología ni, de manera más amplia, razón y fe, sino que se trata de construir la experiencia -sapiencial, esto es, informada por el amor- de búsqueda de lo que son las cosas.

La posibilidad de una armonización y reconocimiento mutuo de fe y ciencia se logra al reparar en que "el hombre es una unidad y no es posible salvarlo si se lo divide en muchas partes" (Panikkar, 2014: 133). Precisamente por su desmembramiento, por ejemplo, por "la división tajante alma-cuerpo es que la medicina 'con menos frecuencia cura al enfermo y casi nunca al ser humano"' (Martínez Bejarano, 2016: 177), en la analogía que Panikkar establece entre medicina y religión, lo cual es digno de considerar tanto por parte de la medicina como por la psicología actuales. Ya el hombre moderno asesinó a un Dios aislado y distante, totalmente alejado y retirado del mundo, y la Tierra está acabando con un hombre codicioso y sin piedad que sólo se preocupa de sí y entiende lo real como mero recurso de explotación. El desafío para el nuevo siglo radica en superar 
estas fragmentaciones, la segmentación de ámbitos heterogéneos que viven de espaldas unos a otros, que lleva en último término a la desintegración de cada uno de ellos, pues el ser humano no se satisface con aspectos parciales, sino que sólo una simbiosis de todos los ámbitos de la vida (cósmico, humano y divino) puede acoger a esta de manera cabal.

\section{REFERENCIAS}

Ariso, J. M. (2015). Some variations of the certainty of one's own death. Linguistic and Philosophical Investigations, 14, 82-96.

Ariso, J. M. (2019) Can a culture of error be really developed in the classroom without teaching students to distinguish between errors and anomalies? Educational Philosophy and Theory, 51(10), 1030-1041.

Chavarría Alfaro, G. (2015). El posthumanismo y los cambios en la identidad humana. Reflexiones, 94(1), 97-107.

Cirlot Valenzuela, V., Melloni, J., Tamayo Acosta, J. J. \& Saranyana Closa, J. I. (2018). 2018, el año Panikkar. El Ciervo: revista mensual de pensamiento y cultura, (769), 16-19.

Fundación Vivarium Raimon Panikkar (s.f.). Raimon Panikekar. El sitio oficial. Disponible en http://www.raimon-panikkar.org/spagnolo/home.html

García Norro, J. J. (2014). De cómo nuestros cerebros crean la belleza, el bien y la verdad. Revista de libros, 186. Disponible en http://www.revistadelibros.com/articulos/de-como-nuestros-cerebros-crean-la-belleza-el-bien-yla-verdad

Gehlen, A. (1980). El hombre. Salamanca: Sígueme.

Gervilla Castillo, E. (2003). Pedagogía del esfuerzo y cultura del placer. Revista Española de Pedagogía, (224), 97-114.

Gómez, C. M. (2015). La hermenéutica intercultural de Raimon Panikkar. Franciscanum, 57(164), 19-43.

Heidegger, M. (1994). La pregunta por la técnica. Barcelona: Ediciones Serbal.

Hottois, G. (2013). Humanismo, Transhumanismo, Posthumanismo. Revista Colombiana de Bioética, 8(2), 167-192.

Inciarte, F. (2004). Imágenes, palabras, signos. Sobre arte y filosofía. Pamplona: EUNSA. Inciarte, F. (2016). Cultura y verdad. Pamplona: EUNSA.

Kasak, E. (2018). On a productive dialogue between religión and science. Scientia et Fides, 6(1), 129-153.

Llano, A. (2013). Representacionismo y lenguaje. En J. Arana (Ed.), Falsos saberes. La suplantación del conocimiento en la cultura contemporánea (pp. 213-222). Madrid: Biblioteca Nueva.

López Eire, A. (1995). Retórica antigua y retórica moderna. Humanitas, XLVII, 871-907.

Maritain, J. (1942). Humanismo Cristiano. Fortune Magazine. Disponible en http://www.jacquesmaritain.com/pdf/08_HUM/13_H_HumCrist.pdf

Martínez Bejarano, N. (2016). Reseña de R. Panikkar, La religión, el mundo y el cuerpo. Ideas y valores: Revista Colombiana de Filosofía, 65(nº extra 2), 175-178. 
Millán-Puelles, A. (1967). La estructura de la subjetividad. Madrid: Rialp.

Millán-Puelles, A. (2009). Las dimensiones morales del interés por la verdad. Anuario Filosófico, XLII(3), 531-553.

Nieto, S. (2018). Karen Armstrong: "La religión es un consuelo necesario; desesperados, hacemos cosas terribles". $A B C, 2$ de noviembre. Disponible en https://www.abc.es/internacional/abci-karen-armstrong-religion-consuelo-necesario-desesperados-hacemos-cosas-terribles-201810270319_noticia.html

Taylor, C. (2016). La ética de la autenticidad. Barcelona: Espasa.

Orrego Sánchez, C. (2015). Fe y razón en la filosofía católica: la propuesta de Alasdair MacIntyre. Veritas, (33), 9-23.

Ortega y Gasset, J. (1983). ¿Qué es filosofía? En Obras completas (vol. VII; pp. 182191). Madrid: Alianza Editorial-Revista de Occidente.

Panikkar, R. (1961). Ontonomía de la ciencia. Sobre el sentido de la ciencia y sus relaciones con la filosofía. Madrid: Gredos.

Panikkar, R. (1993a). La nueva inocencia. Estella: Verbo Divino.

Panikkar, R. (1993b). La visión cosmoteándrica: el sentido religioso y emergente del tercer milenio. Qüestions de Vida Cristiana, (156), 78-102. Disponible en http://www.seleccionesdeteologia.net/seleccines/llib/vol32/125/125_panikkar.pdf

Panikkar, R. (1999). The Intrareligious Dialogue. Nueva York: Paulist Press.

Panikkar, R. (2005). De la mísica. Experiencia plena de la vida. Barcelona: Herder.

Panikkar, R. (2006a). Emanciparse de la ciencia. En A. Ortiz-Osés y P. Lanceros (Eds.), La interpretación del mundo. Cuestiones para el tercer milenio (pp. 53-76). Barcelona: Anthropos.

Panikkar, R. (2006b). Paz e interculturalidad. Una reflexión filosófica. Barcelona: Herder.

Panikkar, R. (2007). Mito, fe y hermenéutica. Barcelona: Herder.

Panikkar, R. (2009). La puerta estrecha del conocimiento. Sentidos, razón y fe. Barcelona: Herder.

Panikkar, R. (2014). La religión, el mundo y el cuerpo. Barcelona: Herder.

Papastephanou, M. (2003). Forgiving and Requesting Forgiveness. Journal of Philosophy of Education, 37(3), 503-524.

Pérez Prieto, V. \& Meza Rueda, J. L. (2016). Diccionario Panikkariano. Barcelona: Herder.

Piirto, J. (2011). Creativity for 21st Century Skills. How to Embed Creativity into the Curriculum. Rotterdam/Boston/Taipei: Sense Publishers.

Platón (1871). Fedro. En Obras completas (tomo II). Madrid: Medina y Navarro.

Quevedo, A. (2013). Un antiguo sustituto del conocimiento. Raíces del concepto heideggeriano de curiosidad. En J. Arana (Ed.), Falsos saberes. La suplantación del conocimiento en la cultura contemporánea. Madrid: Biblioteca Nueva.

Sánchez Cañizares, J. (2008). Razón y fe en la fundación del comprender. Reflexiones desde el magisterio de Benedicto XVI. Scripta Theologica, 40(3), 859873. 
Senent De Frutos, J. A. (2019). Modernidad, formación universitaria y espiritualidad. Una lectura intercultural desde la tradición jesuita. Concordia, (75), 85101.

Vilanova, E. (1993). Prólogo. En R. Panikkar, La nueva inocencia (pp. 9-24). Estella: Verbo Divino.

Sumario: 1. ¿Homo culturalis y homo religiosus a la vez?; 2. La fe como dimensión constitutiva humana; 3 . El pensamiento científico; 4. El principio de la ciencia: la presencia de lo real como momento contemplativo; 5 . Una condición trágica elevadora; 6. La ciencia opaca; 7. Una diversidad de lenguajes; 8. Dos posibles comprensiones del mundo; 9. Conclusión; Referencias. 